\title{
Barriers for Industrial Sensor Integration Design-An Exploratory Interview Study
}

\author{
Juul-Nyholm, Herle Bagh; Ebro, Martin; Eifler, Tobias
}

Published in:

Journal of Mechanical Design

Link to article, DOI:

$10.1115 / 1.4050078$

Publication date:

2021

Document Version

Peer reviewed version

Link back to DTU Orbit

Citation (APA):

Juul-Nyholm, H. B., Ebro, M., \& Eifler, T. (2021). Barriers for Industrial Sensor Integration Design-An

Exploratory Interview Study. Journal of Mechanical Design, 143(7), [074501]. https://doi.org/10.1115/1.4050078

\section{General rights}

Copyright and moral rights for the publications made accessible in the public portal are retained by the authors and/or other copyright owners and it is a condition of accessing publications that users recognise and abide by the legal requirements associated with these rights.

- Users may download and print one copy of any publication from the public portal for the purpose of private study or research.

- You may not further distribute the material or use it for any profit-making activity or commercial gain

- You may freely distribute the URL identifying the publication in the public portal

If you believe that this document breaches copyright please contact us providing details, and we will remove access to the work immediately and investigate your claim 


\title{
Barriers for Industrial Sensor Integration Design - an Exploratory Interview Study
}

\author{
Herle Bagh Juul-Nyholm* Martin Ebro \\ Ph.D. Student Senior Manager \\ Engineering Design \& Product Development Engineering Analysis \& Materials \\ Department of Mechanical Engineering Device R\&D \\ Technical University of Denmark Novo Nordisk A/S \\ Kgs. Lyngby, DK-2800 Hillerød, DK-3400 \\ Email: hbaju@mek.dtu.dk
}

\author{
Tobias Eifler \\ Associate Professor \\ Engineering Design \& Product Development \\ Department of Mechanical Engineering \\ Technical University of Denmark \\ Kgs. Lyngby, DK-2800
}

The transition to Industry 4.0 poses new challenges for sensor integration design. The foundation of any intelligent system is the data, and the data quality depends largely on the integration of the sensor generating it. In this study, the barriers for robust sensor system design were explored through an interview study among practitioners from different industrial contexts. The aim is to explore potential challenges within different contexts and suggest possible directions for research within the field of sensor integration design. Beyond the question of new sensing technologies, the study highlights an increasing challenge of physical integration task, and illustrates the varying requirements for development support in different industry sectors.

\section{Introduction}

IoT-devices promise immense business value across a wide range of industry sectors. Examples are rapid transformation of customer-product interactions or traditional industry structures as part of the Fourth Industrial Revolution (Industry 4.0). Yet, the aspect that the ability to unlock this potential will pose completely new challenges for engineering design is frequently neglected.

Due to the exponential development of semi-conductor technology like sensors, actuators and computers, these technologies are getting integrated into mechanical products for digital monitoring and control on an unprecedented scale. This naturally results in completely new requirements with respect to size, efficiency and cost, and thus for the integra-

${ }^{*}$ Corresponding author tion of the mechanical, electrical and software domains. It is well accepted, that the integration of multiple disciplines alone, for example in mechatronic development, adds substantial complexity and risk to design projects and organizations [1-4]. However, given the unprecedented scale of the current transition, contextual influences will result in more diversity when it comes to the experienced challenges in engineering design.

Against this background, this research focuses particularly on engineering design challenges related to sensor integration tasks, i.e. on the ability to reliably measure physical input and convert it to analogue or digital data that can be processed by either machine or human. The robustness of the sensor integration is a necessary prerequisite for the transition to Industry 4.0, where the responsibility for safe and optimal functionality of systems is transferred from humans to technical systems. In this paper, the current industrial challenges and practices are described as seen by the industrial practitioners. This is achieved through an exploratory study, using semi-structured interviews to identify the main themes within challenges and practices with sensor system design and sensor integration tasks.

The remainder of the paper is structured as follows. In Section 2, a short literature review focusing on design practices is presented. In Section 3, the research methodology and design is introduced. In Section 4, the interview findings are presented, both related to contexts and on a general level. In Section 5, the implications of the interview findings are discussed. At last, Section 6 summarizes the content of the paper. 
2 Literature Review on Sensor System Design Practices

Engineering design is generally concerned with the realisation of technical products. This includes the conceptualization of basic solution principles as well as the embodiment of shapes, materials and structures to achieve the intended functions. To do this, the initial goal is to compare and assess a wide range of design alternatives by exploring the solution space in a divergent manner and consecutively converge, select and focus the embodiment efforts on the most promising design candidate.

Mechatronic design literature extends this fundamental idea towards a multi-disciplinary design approach that has emerged as sensing and actuation technology has become available for integration into mechanical products. For example, Mohebbi et al. [5] review trends in concurrent, multi-criteria and optimal design of mechatronics systems, and highlight that academic and industrial design challenges for mechatronics to a large extent also relate to conceptual and preliminary design stages. Another example is TorrySmith et al. [1,2], stating that a lack of sufficient attention to the [multidisciplinary, auth.] dependencies causes integration problems and increased development cost [1]. One important aspect of promising design candidates is consequently the ability to achieve robust functional performance as this reflects on the quality of the final product. This aspect is the focus of Robust Design, where quality is defined as the achievement of high product performance despite noise factors from manufacturing and use [6]. Traditionally, Robust Design has focused on achieving design quality through parametric optimisation, but several authors have highlighted the need for what is referred to as Robust Design Methodology (RDM). Adopting the fundamental engineering design idea, RDM prescribes basic and systematic efforts applicable in all development phases to achieve consistent mechanical product performance despite noise factors [7-9].

Unfortunately, RDM research does not yet include mechatronics, like sensor systems, to a large extent. Instead, and in line with traditional Robust Design approaches, mechatronics design relies heavily on computational parameter optimization [10-12], or analytical and numerical analyses of noise factor contributions [13-15]. As these approaches are however not suited for early design assessments [16,17], the design of sensor systems usually refers to data sheets. These describe the accuracy of standard, commercially available sensor units, i.e. the performance variation [18] along with specifications on environmental conditions and integration.

While these specifications indicate what the manufacturer expects from the sensor design in use, they naturally do not provide insight into the full suite of the considered noise factors. Depending on the requirements and the novelty of the IoT-application, the sensor performance will be more or less defined by a range of case specific noise factors. However, contributions on the methodical design of sensors are rare and in most cases out-dated, as also highlighted in a review on the importance of mechanical design for sensor systems by Juul-Nyholm et al. [19]. Examples include Carr introducing a framework for sensor system noise factors [20] and Ellin and Dolsak [21] as well as Macini et al. [22] describing interdisciplinary noise factors for encoders.

\section{Methodology}

\subsection{Research Question and Design}

The aim of the study was to address the current challenges with sensor system design in different industrial contexts in order to identify gaps in the current practices. The exploration was guided by the following research question:

\section{What are typical sensor system design challenges in the industrial context of sensing elements, in- dustrial products and consumer products?}

The focus on contextual challenges led to the choice of a semi-open elite interview format, which allowed for exploration and insights for development of new hypotheses rather than numerically based testing of existing hypotheses [23-25]. Interviews allow for a retrospective view on a long chain of events and thereby for exploration of the past and recent experiences of the interviewees. This backwardlooking perspective is important, because this study focuses on the risks and consequences of late-stage design changes, complaints and recalls of design projects, which would not necessarily be covered in a contemporary case study. On the other hand, interviews are restricted to information that the interviewees are able to articulate - the explicit, biased and rational design knowledge. Gathering implicit and tacit knowledge would require other means of inquiry like document, discourse or protocol analysis [26]. However, focusing on explicit knowledge is a necessary disadvantage of gathering data from a range of different interviewees and companies seeking to represent the current industrial situation in the light of both history and present contexts.

\subsection{Case Companies and Interviewees}

Four case company categories were chosen for the study: Sensing element companies (four companies, six interviewees), consumer product companies (three companies, five interviewees), industrial product companies (three companies, five interviewees) and consultancies (three companies, four interviewees). The 20 interviewees had mixed technical backgrounds ranging from mechanics and electronics to physics and chemistry as well as up to 30 years of experience with the development of sensor systems. The 13 case companies were all located in Europe and were chosen based on the company categories and their willingness to participate. The four case company categories represent different roles in the evolving IoT and Industry 4.0 industry in terms of engineering design of sensor systems. They include relevant design practitioners in B2B and B2C as well as sensor suppliers, and exclude regulatory bodies, which are not involved directly in the research and development of new sensor system designs. Other characteristics than the core product, like size, application field, geography and tradition, presumably also contribute to diversity in challenges 
and practices to varying degrees, but for the sake of simplicity only the core focus and the production/project volume was taken into account in the selection process.

The sensing, consumer and industrial products differ in application and level of specialisation. Sensing element companies offer standard and custom sensing solutions through both direct and indirect sale and have a high production volume. They are experts in the conversion of physical phenomena to analog or digital outputs, but have limited control in the integration of their sensors into systems. Consumer product companies operate under a high demand for the products' industrial design, feature set, and size and have an indirect interaction with their customers that use their products in an everyday setting. They have a high production volume and it is assumed that many consumer products are increasingly made smarter by adding sensors and connecting them to smartphones and other software-based systems. Industrial product companies' production volumes vary, they have a more direct interaction with their customers and are not subject to as high demands regarding size and appearance. Sensors have been used for control purposes for a long time, but with Industry 4.0 the demand for manufacturing customization and large scale data analysis is increasing. Consultancies come in different company sizes and support the product manufacturing companies with subject specific expertise. For the purpose of exploring contextual influences on challenges and practices, interviewees from consulting companies are also interesting because they have a broader experience with different contexts.

\subsection{Interviews}

The interviews were structured according to the interview themes presented in Tab. 1 along with a few example questions. They were scheduled to one hour including a short introduction to the purpose and format of the interview and were all recorded for subsequent compilation of notes and quotes. At last, the quotes and case summaries were sent to the interviewees for confirmation.

The first interview theme focused on the context and professional background of the interviewees. These questions were used as grand tour questions and formal introductions [27]. The challenges and consequences theme was intended to identify the most critical challenges and get insights into how they emerged and what the consequences were. The questions about practices dealt with development processes, the practices with assessing multi-physical effects and the influence of variation. The aim was to understand how the case companies successfully develop and launch new products despite the expressed challenges. At last, if time allowed, a question on methodical gaps served as a closure to the interview.

The data analysis was initiated by inductively identifying general themes through disassembling and reassembling of the challenges and practices expressed by the interviewees. This approach was chosen in order to identify challenges and practices across contexts and reduce the interviewer bias. First, the compiled interview notes were disas- sembled [28], i.e. the data was broken down into sentences or terms in order to isolate them from the context and rearrange them with fresh eyes. Then, the reassembly [28] was performed on an individual basis by two of the authors to assess the inter-coder reliability qualitatively. The themes were compared and in most but not all cases the themes were overlapping and even had the same name. The challenges were easily reassembled while the practices were more scattered and hard to reassemble. Subsequently, the themes were synthesised collectively. The themes presented in Section 4.1 focus on general challenges as comparison and categorization of contextual influences was inconclusive at this conceptual level.

The deductive mapping of contextual challenges and practices was based on the interest in the increasing integration of emerging sensing technologies. The deductive approach was chosen in order to specifically investigate the relation between the company categories and the two dimensions; physical sensing integration and technological sensing focus (hereafter referred to as physical integration and technological focus). The categorization was based on the company profiles (available in the Appendix) as these summarize the most apparent contextual challenges. The dimensions were defined based on a textbook definition of integral product architecture as opposed to a modular one [29] and on the responses from the introductory interview questions. Consequently, shallow physical integration was coded when the interviewees described that they were retrofitting sensors, mounting off-the-shelf sensors or designing sensors with standard interfaces, and deep physical integration was coded when the interviewees expressed challenges with interacting variation effects and size constraints. Technological sensing focus was defined based on the responses to the sensor type question (second question in Tab. 1). If the interviewees responded that they use one or very few technologies the company was categorised as having a narrow technological focus and vice versa.

\section{Findings}

\subsection{General Challenges}

Based on the inductive mapping of interview extracts, challenges and reasons for the associated consequences were compiled. Themes and subthemes are listed in Tab. 2 and are introduced in the following.

\section{Evolution of Technology}

The interviewees reported three subthemes for challenges related to the evolution of technology. First, the companies are forced to constantly develop their use of novel technologies to comply with market demands. In some cases this implies a continuous release of product updates, while groundbreaking and innovative solutions are the focus in others. Second, some companies utilise a wide range of technologies and struggle to keep updated on the latest advances within all fields. This is often a matter of prioritisation and resources, but is nonetheless an expression of challenges 


\begin{tabular}{ll}
\hline Interview theme & Example Questions \\
\hline Background & What is your background and current role? \\
& What types of sensor systems are your working with? \\
Challenges and consequences & $\begin{array}{l}\text { Are you experiencing any challenges with design of sensor systems? If yes, what } \\
\text { types? } \\
\text { What are the consequences of these challenges? }\end{array}$ \\
\hline Practices & $\begin{array}{l}\text { How and when do you assess the influence of variation effects? } \\
\text { How and when do you assess the influence of multi-physics effects? }\end{array}$ \\
\hline Methodical gaps & What kind of tool or method are you missing? \\
\hline
\end{tabular}

with maturing and familiarisation of technologies. Third, some companies lack the experience of using sensing technologies due to a traditional analog product focus.

\section{Physical Integration}

Some case companies highlight physical integration, as opposed to exclusively digital integration, as a central design challenge. First, it is crucial to find the balance between development efforts and profits, because physical integration can increase the product value, but also complicates the development process and the ability to calibrate the sensor system. Another reason is requirement trade-offs both on a high and more detailed level. For example trade-offs between accuracy and manufacturability, between maintaining original functions while adding sensor technology or between conflicting design objectives in different engineering domains. Third, designers tend to focus inherently on their own domain of expertise. This leads to challenges in the development of products with inter-disciplinary interfaces, because no one in the team is specialised in e.g. electro-mechanical interfaces but rather in mechanical processes or circuit design. Fourth, size constraints can be imposed on a design both in retrofitting projects and due to requirements to appearance, handling, transportation or application, and may even lead to the need for deep physical integration. Fifth, when physical integration is needed, for any reason, the variation in mechanical manufacturing processes can lead to performance variations that are sometimes hard to assess and take into account.

\section{Requirement Specifications}

Requirement specifications are central to all product development processes. Nevertheless, the interviewees expressed three specific challenges that apply to the development of sensor systems. First, most companies expressed challenges with gathering all relevant requirements from the customers - especially the specific ones related to environment and operation. This is both due to organizational barriers between the customer and development department, and the inherent focus on the function of the sensor system rather than total product operation in requirement specification meetings. Second, there is a lack of detailed technological guidelines as the use of technologies is constantly pushed to the limits in order to meet market demands, which means that available standards and guidelines fail to account for novel technological applications. Third, novel technological applications are associated with challenges of prediction of noise factors and specification of reasonable limits and safety factors.

\section{Virtual Design Assessments}

In the design assessments category, four types of challenges with modeling, simulating and testing of sensor systems before they are built physically could be distinguished. First, many interviewees mentioned how Failure Mode and Effect Analyses (FMEA) are used in early development stages to identify reliability issues and to address them with due diligence. Unfortunately, the FMEAs are traditionally designed for specific disciplines, why interdisciplinary failure modes and effects are sometimes overlooked. Second, methods for early robustness assessment of mechanical assemblies are applied by some companies, but are lacking for electronics, software and multi-disciplinary systems. Third, with more mature designs, numerical multi-physics simulations are applied to a varying degree by the case companies. However, several interviewees relate that they are often oversimplified and sometimes lead to unfortunate design decisions and delays. Fourth, multi-physics simulations often also require subject matter experts for setup and are perceived as much less efficient than physical tests and single domain simulations.

\section{Physical Design Assessments}

Physical testing is central to the development of sensor systems and the interviewees pointed to three general challenges with this. First, some companies follow formalized test plans meticulously while others express challenges with defining appropriate tests. Generally, the companies place 


\begin{tabular}{|c|c|c|}
\hline Main theme & & Subtheme \\
\hline 1. Challenges with the evolution of technology & due to & $\begin{array}{l}\text { - market competition } \\
\text { - a wide technological focus } \\
\text { - lack of experience }\end{array}$ \\
\hline 2. Challenges with physical integration & due to & $\begin{array}{l}\text { - cost and calibration barriers } \\
\text { - trade-offs between requirements } \\
\text { - inherent focus within engineering domains } \\
\text { - size constraints } \\
\text { - variation in mechanical processes }\end{array}$ \\
\hline 3. Challenges with requirement specifications & due to & $\begin{array}{l}\text { - lack of customer input } \\
\text { - lack of detailed technological guidelines } \\
\text { - extreme and unpredictable applications }\end{array}$ \\
\hline 4. Challenges with virtual design assessment & due to & $\begin{array}{l}\text { - lack of interdisciplinary models for early assessment } \\
\text { - lack of multi-disciplinary robustness principles } \\
\text { - lack of trust in multi-physics simulations } \\
\text { - lack of efficient multi-physics simulations }\end{array}$ \\
\hline 5. Challenges with physical design assessment & due to & $\begin{array}{l}\text { - lack of confidence in test schemes } \\
\text { - lack of access to field tests } \\
\text { - comprehensive product validation }\end{array}$ \\
\hline 6. Above challenges have consequences & due to & $\begin{array}{l}\text { - delays between design and assessment activities } \\
\text { - lack of multi-disciplinary robustness principles } \\
\text { - the cost of changing electronic hardware in remote locations }\end{array}$ \\
\hline
\end{tabular}

great emphasis on dynamic and environmental noise factors, while Carr's [20] characteristics and application categories are not widely considered. Second, the majority of the companies use physical component and system tests to assess the functionality of their design at different stages, yet some have limited access to test in the field. This is due to the size of the products, critical operations or the fact that the products are commissioned remotely or inaccessibly. Third, some sensor systems are part of critical operations that require very comprehensive validation tests, which are both expensive in terms of materials and time.

\section{Consequences of Above Challenges}

The consequences of the general challenges above differed, but three tentative reasons for delays in relation to sensor system design were identified. First, the inefficiency of virtual and physical tests leads to delays between design and assessment. Many interviewees stressed how important it is to prototype the whole sensor system as early as possible to avoid wasting development efforts. Second, the interviewees reported that delays due to design challenges were more severe if design changes require changes in the mechanics, because in this domain it is both expensive and time consuming to change production tools. Third, the cost of changing hardware as opposed to updating software is high, because it requires a technician to be on site as opposed to initiating over-the-air updates.

\subsection{Contextual Challenges}

In order to explore the effects of contextual differences on experienced challenges and practices, the case companies were categorized according to a matrix typology. The typology was based on two axes, physical sensing integration and technological sensing focus, as defined in Section 3.3, and can be seen in Fig. 1 .

It is observed that the case companies are categorized similarly within the core product groups, except for the industrial case companies. The sensing element companies all have a shallow physical sensing integration, because of their focus on sensing rather than system. Their technological sensing focus varies due to specialization and tradition. Sensor system consultancies support companies with the physical and digital integration of sensors, resulting in a focus on a wide range of technologies. The difference between shallow and deep physical integration may be due to the differences in project volume (i.e. company size). The consumer product companies focus on few sensing technologies as well as a deep and size-constrained integration. They are seeking to 


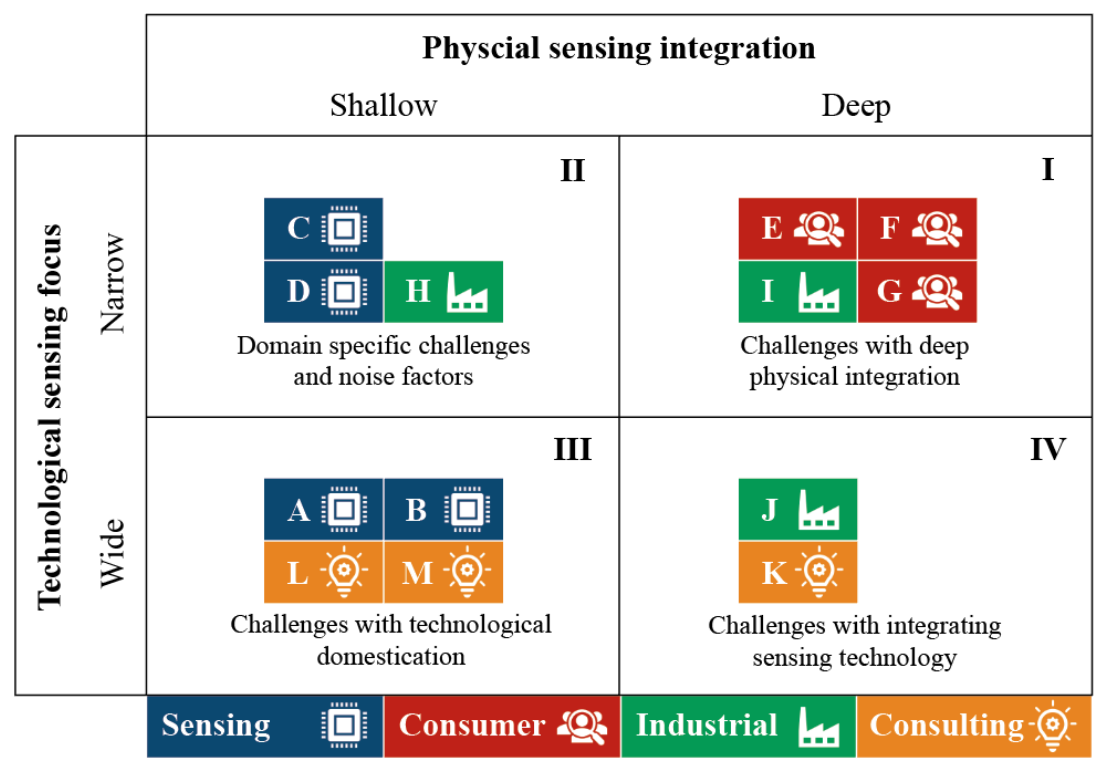

Fig. 1. Matrix typology for Companies A-M. Common challenges are included in each quadrant, I-IV.

retain and enhance it by adding sensors to their systems. The industrial product companies are represented in quadrants I, II and IV, which may be due to the production volume, but this will also be discussed in greater detail later.

As indicated in the matrix typology, the interviews illustrate that the integration and technological context has an influence on the sensor system design challenges. Four contextual challenges have been identified based on a summary of the interviews in the company profiles and linked to the four quadrants of the typology matrix.

\section{Challenges with deep physical integration}

All case companies in quadrant I expressed their challenges with deep physical integration through detailed descriptions of their past experiences with inter-disciplinary interactions on both interface as well as system level. One of the main drivers for the deep physical integration is that all companies have high production volumes. The corresponding high demands in terms of size and cost increase the number of trade-offs between the newly added connectivity and the existing product functions or the customer's quality perception. Most often, these become apparent at the boundaries between mechanical, electrical, and software development, and are particularly critical when the service-life cannot be predicted in all details. A consequence is that the technological sensing focus of all companies in quadrant I is still narrow. The application of the sensing is very specific, the technological evolution has only led to applicable sensor sizes in recent years, and the companies are often still struggling to balance the numerous requirements with the initially chosen sensing technology. The company profiles can be seen in Tab. 3 in the Appendix.

\section{Domain specific challenges and noise factors}

The case companies in quadrant II have a clear focus on domain specific challenges with noise factors like vibration, dust and wear as well as mechanical joining processes such as gluing and welding. The underlying reason is that their choice of sensing technologies is based on tradition and that they have a strong knowledge base with their systems. The companies design or employ sensing modules for integration in mechanical products of different shapes and sizes, most often based on standard interfaces and standardised requirement documents, which also allows for retrofits. As a consequence, the sensing companies often draw from previous designs and rely on sophisticated assessment possibilities, including multi-physics simulations, and the industrial company choose and mount sensors late in the design process. Given that the system interdependencies are well-described, the development focus usually lies more on the qualification of individual components rather than the investigation of integration effects. The company profiles can be seen in Tab. 4 in the Appendix.

\section{Challenges with technological domestication}

The case companies in quadrant III expressed challenges with domestication of technologies in two ways; either from a basic physical perspective or from a practical and case specific perspective. They specialize in bringing new sensor types and digital integration technologies to the market and making them work in a wide range of applications. In both cases, short development iterations are needed, which is usually addressed by the design and employment of modules and, in most cases, the implementation of a pre-qualification of individual components. While this includes simulation and testing, the companies unanimously bring up the challenge of meaningful simulations when a strong theory domain for new technologies is lacking. As a result, all companies in quadrant III follow a test oriented development pro- 
cedure. The company profiles can be seen in Tab. 5 in the Appendix.

\section{Challenges with integrating sensing technology}

Both companies in quadrant IV expressed challenges with the use and integration of sensing technologies in novel applications and were aware of the trade-off between the development of a sensing module as opposed to custom development of sensors with deep physical integration. They excel at their desire to cover a wide range of technologies while venturing into the deep physical sensing integration when necessary. At the same time, the companies differ significantly on a wide range of other dimensions, including not only their industry sector, but also aspects such as product size, testing possibilities, production volume, etc. The question how the companies meet the demands and solve the trade-off between new technology and deep physical integration will therefore be part of the discussion. The company profiles can be seen in Tab. 6 in the Appendix.

\section{Discussion}

\subsection{General and Contextual Challenges}

The general challenges identified in the previous section revolve around the interview focus on integration and design assessments, but also include insights into the challenges of keeping up with the technological evolution and specifying requirements, which was not probed for specifically. The typology sorts consumer, sensing, and consulting companies consistently. However, the industrial companies are spread out into three quadrants, showing larger and more significant differences than for example the consumer companies, which all focus on small, handheld devices and therefore, presumably, have more in common in terms of sensor system design challenges as well. Additionally, the historical perspective is important in the comparison between industrial and consumer companies, as the size of sensing elements is less critical in some industrial applications than in consumer products. Therefore, they have been utilized earlier without the need for deep physical integration.

Furthermore, the companies in quadrant IV are neither directly comparable to each other nor their respective case company categories. Company $\mathrm{J}$ focuses on maturing of technology for low volume and for remote and harsh environments, while Company $\mathrm{K}$ focuses on medical devices and on pre-qualification of components for any project relevant to their costumers (see Tab. 6 in Appendix). On the other hand, they both deploy a wide range of existing sensor types in new applications and revert to deep integration when necessary. This justifies their common categorization but also indicates that they are not always expanding the technological width and integration depth at the same time. Rather, they show similarities with both quadrant I and III at times, which adds to the discussion of the categorization of industrial companies.

\subsection{Identification of Methodical Barriers}

The responses on the interview questions about practices were scattered and hard to categorize. This is most probably due to contextual differences, and is the reason that the following discussion on methodical barriers is based on anecdotal quotes.

All companies in quadrant I (Fig. 1) work with deeply integrated systems, which results in challenges to work with standard design methods or standard textbook knowledge. For example, one interviewee (Company G) explicitly stated that their efforts to design a robust and low cost sensor system required them to challenge what is written in the educational books. In other words, some rules of thumb may be overly conservative or too general for actually solving challenges related to the desired deep physical integration.

Similarly, companies in quadrant II and III experience challenges to increase the level of physical integration. Depending on the business context, not all companies experience this need (Company $\mathrm{H}$ ), but some have actually tried (Company C) and not succeeded a few times as stated in the summary in Tab. 4 in the Appendix. At the same time, most of the corresponding companies instead highlight the challenge of detailed validation activities, such as simulation and/or physical testing, which Company $\mathrm{C}$ describes in relation to welded and glued interfaces.

In quadrant III, the focus on technological domestication is achieved largely through physical tests. Here, the companies, however, also highlight that domestication and integration are closely related. For example, one interviewee from Company $\mathrm{M}$ related that sensors outputting raw data or environmental data are less challenging to integrate than sensors that needs to output processed data or needs to be mounted in a special way, e.g. position sensors (Tab. 5 in App.).

Last but not least, the companies in quadrant IV cover both a wide range of technologies and revert to deep physical integration when relevant. A strategy for achieving both, at least with small production volumes, is to focus on making things work and following it after launch. One interviewee from Company I for example related that they do not test variation at any point, but rather sell to selected customers at first and follow the product closely in operation.

This practice of following products closely after launch is general practice among the industrial companies (not necessarily for the entire product portfolio), but is not achievable for consumer and medical products as they are distributed through different and less controllable channels. In addition, they face high production volumes, which seems to be one of the main drivers for methodical (robust) design support.

Most consumer and industrial companies are placed in the deep end of the physical integration scale. It is the impression that these companies (E, F, G, I and J) are the ones striving mostly to extend the use of sensing technologies through deeper integration and hence are the ones demanding the most flexibility within this typological framework. The sensing element companies mostly focus on technological development including digital and housing solutions, and the consultancies have given a valuable insight into high level trade-offs like domain partitioning and sensor familiariza- 
tion.

\subsection{Future Work}

The concluding interview question, what kind of tool or method are you missing?, had the purpose of letting the interviewees summarise the interview sessions as well as pointing towards specific methodological gaps. It mostly resulted in responses like We have enough methods and tools. Making them valuable in the present context that is the art of it. This indicates that the mitigation of challenges and the improvement of practices is not just a matter of extending the potential toolbox, but also requires meaningful implementation based on the discussion of challenges above. However, several interviewees did express interest in being able to decrease the number of physical tests through the use of virtual models, having more reliable procedures for requirement specifications, reviews and tests, and being able to assess the potential of new technologies more efficiently. This reflects that the barriers for industrial sensor integration design are both technical, organisational and human. In order to develop practical tools and effective methods for sensor system design, the basic knowledge about interdisciplinary dependencies and modelling approaches for specific sensing technologies is needed. Depending on the sensing technology, the basic knowledge is most probably available, if not in literature then in industrial practice, but have not been synthesised and forged into a useful tool. Therefore, future work includes studies of industrial sensor system design cases to get a more detailed understanding of the identified challenges and develop design supports based on this knowledge. Future work also includes investigations of design challenges in relation to connectivity and intelligent manufacturing in the transition to Industry 4.0.

Due to the semi-structured interview approach data consisted only of explicit, qualitative knowledge. The chosen approach for the current study was in line with exploratory aim of the study, as it allowed the interviewees to be the experts and to inform the research [24]. Nevertheless, future work should include multiple data sources like documents and observations, which will improve the validity [23].

\section{Summary}

The aim of this study was to explore the sensor system industry and identify typical sensor system design challenges in different industrial contexts. This was sought through an exploratory interview study with 20 interviewees from 13 companies within the following categories: Sensing elements, consumer products, industrial products and consulting. Five general challenges

1. Evolution of technology

2. Physical integration

3. Requirement specification

4. Virtual design assessments

5. Physical design assessments

and four contextual challenges
I Deep physical integration

II Mechanical noise factors and joining processes

III Technological domestication

IV Integration of sensing technologies

were identified. The contextual challenges with deep physical integration and expansion of the technological sensing focus through integration of unfamiliar sensing technologies are highlighted as important topics for further research in sensor integration design. While it is the impression that the remaining challenges are valid, the barrier of integration of sensing technologies deep into the physical structure of a product is highlighted. This is because the adoption of technologies for IoT and Industry 4.0 is moving at a slow pace in this area due to lack of tools and experience in the development of connected consumer and industrial products. Future work includes synthesizing of basic knowledge of mutual influences and noise factors across engineering domains.

\section{Acknowledgements}

The authors would like to thank the case companies and interviewees for their insightful contribution to this research and Novo Nordisk for financial support to the DTU-NN Robust Design program.

\section{References}

[1] Torry-Smith, J.M., Mortensen, N.H. and Achiche, A., 2013. "Challenges in designing mechatronic systems". Journal of Mechanical Design, 135(1), pp. 53-74. doi: 10.1115/1.4007929.

[2] Torry-Smith, J.M., Qamar, A., Achiche, S., Wikander, J., Mortensen, N.H., and During, C., 2013. "A proposal for a classification of product-related dependencies in development of mechatronic products". $R e$ search in Engineering Design, 25, p. 011005 . doi: 10.1007/s00163-013-0161-5.

[3] Aceto, G., Persico, V., and Pescapé, A., 2020. "Industry 4.0 and health: Internet of things, big data, and cloud computing for healthcare 4.0". Journal of Industrial Information Integration, 18(100129). doi: 10.1016/j.jii.2020.100129.

[4] Sabry, S. S., Qarabash, N. A., and Obaid, H. S., 2019. "The road to the internet of things: a survey". In 2019 9th Annual Information Technology, Electromechanical Engineering and Microelectronics Conference (IEMECON), pp. 290-296. IEEE. doi: 10.1109/IEMECONX.2019.8876989.

[5] Mohebbi, A., Baron, L., Achiche, S., and Birglen, L., 2014. "Trends in concurrent, multi-criteria and optimal design of mechatronic systems: A review". In Proceedings of the 2014 International Conference on Innovative Design and Manufacturing (ICIDM), IEEE, pp. 88-93. doi: 10.1109/IDAM.2014.6912676.

[6] Taguchi, G., Chowdhury, S. and Wu, Y., 2005. Taguchi's Quality Engineering Handbook. Wiley \& Sons, Inc. doi: 10.1002/9780470258354. 
[7] Jugulum, R. and Frey, D.D., 2007. "Toward a taxonomy of concept designs for improved robustness". Journal of Engineering Design, 18(2), pp. 139-156. doi: 10.1080/09544820600731496.

[8] Arvidsson, M. and Gremyr, I., 2007. "Principles of robust design methodology". Quality and Reliability International, 24(1), pp. 23-35. doi: 10.1002/qre.864.

[9] Eifler, T. and Howard, T.J., 2018. "The importance of robust design methodology - case study of the infamous gm ignition switch recall". Research in Engineering Design, 29, pp. 39-53. 10.1007/s00163-0170251-x.

[10] Egel, T., 2009. Robust design of control systems with physical system variances. SAE Technical Paper 200901-1041, SAE International. doi: 10.4271/2009-011041.

[11] Bilel, N., Mohamed, N., Zouhaier, A., and Lotfi, R., 2017. "Multi-objective robust design optimization of a mechatronic system with uncertain parameters, using a polynomial chaos expansion method". Proceedings of the Institution of Mechanical Engineers, Part I: Journal of Systems and Control Engineering, 231(9), pp. 729739. doi: 10.1177/0959651817722333.

[12] Lei, G., Zhu, J., Guo, Y., Liu, C., and Ma, B., 2017. "A review of design optimization methods for electrical machines". Energies, 10(12), pp. 1962-. doi: 10.3390/en10121962.

[13] Akbarzadeh, A., Kouravand, S., and Imani, B. M., 2013. "Robust design of a bimetallic micro thermal sensor using taguchi method". Journal of Optimization Theory and Applications, 157(1), pp. 188-198. doi: 10.1007/s10957-012-0171-x.

[14] Anadkat, N. and Rangachar, M., 2012. "Simulation based analysis of capacitive pressure sensor with comsol multiphysics". International Journal of Engineering Research and Technology,, 4(4), pp. 848-852. doi: 10.17577/IJERTV4IS041064.

[15] Forslund, A., Söderberg, R., Lööf, J., and Galvez, A. V., 2011. "Virtual robustness evaluation of turbine structure assemblies using 3d scanner data". In ASME International Mechanical Engineering Congress and Exposition, Vol. 54877, pp. 157-165.

[16] Alyaqout, S.F., Papalambros, P.Y. and Ulsoy, A.G., 2010. "Combined robust design and robust control of an electric dc motor". IEEE/ASME Transactions on Mechatronics, 16(3), pp. 574-582. doi: 10.1115/IMECE2006-16027.

[17] Villarreal-Cervantes, M.G., Cruz-Villar, C.A., Alvarez-Gallegos, J., and Portilla-Flores, E.A., 2012. "Robust structure-control design approach for mechatronic systems". IEEE/ASME Transactions on Mechatronics, 18(5), pp. 1592-1601. doi: 10.1109/TMECH.2012.2208196.

[18] Nyce, D.S., 2016. Position Sensors. Wiley \& Sons, Inc. doi: 10.1002/9781119069164.

[19] Juul-Nyholm, H.B., Eifler, T., and Ebro, M., 2020. "Robust design for iot - on the relevance for mechanical design for robust sensor integration in connected de- vices". In Proceedings of the Design Society: DESIGN Conference, Vol. 1, Design Society, Cambridge University Press, pp. 235-244. doi: 10.1017/dsd.2020.326.

[20] Carr, J.J., 1993. Sensors and circuits: sensors, transducers, and supporting circuits for electronic instrumentation, measurement, and control. PTR Prentice Hall, Englewood Cliffs.

[21] Ellin, A. and Dolsak, G., 2008. "The design and application of rotary encoders". Sensor Review, 28(2), pp. 150-158. doi: 10.1108/02602280810856723.

[22] Mancini, D., Auricchio, A., Brescia, M., Cascone, E., Cortecchia, F., Schipani, P., and Spirito, G., 1998. "Encoder system design: strategies for error compensation". In Proc. SPIE 3351, Telescope Control Systems III, Vol. 3351, pp. 380-386. doi: 10.1117/12.308835.

[23] Berry, J.M., 2002. "Validity and reliability issues in elite interviewing". In PS: Political Science and Politics, Vol. 35, pp. 679-682. doi: $10.1017 / \mathrm{S} 1049096502001166$.

[24] Leech, B.L., 2002. "Asking questions: Techniques for semistructured interviews". In PS: Political Science and Politics, Vol. 35, pp. 663-664. doi: $10.1017 /$ S1049096502001129.

[25] Cohen, L., Manion, L., and Morrison, K., 2007. Research methods in education, $6^{\text {st }}$ ed. Routledge, New York, Chap. 16, pp. 349-382. doi: 10.4324/9780203029053.

[26] Ahmed, S., 2007. "Empirical research in engineering practice". Journal of Design Research, 6(3), pp. 359380. doi: 10.1504/JDR.2007.016389.

[27] Yin, R.K., 2011. Qualitative Research from Start to Finish. The Guilford Press, New York/London, Chap. 6.C, pp. 132-142.

[28] Yin, R.K., 2011. Qualitative Research from Start to Finish. The Guilford Press, New York/London, Chap. 8, pp. 176-203.

[29] Ulrich, K.T and Eppinger, S.D., 2008. Product Design and Development, $4^{\text {st }}$ ed. McGraw Hill, Chap. 9, pp. 163-186.

\section{Appendix: Company Summaries}


Company $\mathrm{E}$ does not have a product with an integrated sensor on the market yet, and is currently developing its first-ever personal medical care product with enhanced safety based on sensing technology. They have a strong focus on usability. It must look attractive, so the user insights and user experience $(U X)$ design teams have a large influence on the result. And of course it is important, because if it does not look good, then you cannot sell it. It is part of the business case. But the focus is on that and then we are supposed to make something fit in technically, that is designed so that it can be sold. Because of the novelty, they are at the limits of their past abilities and there are no set processes, so planning is difficult. Designing products for personal medical use is different than designing something to be placed on a table, because the environment is harsh and unpredictable. [...] How far should we go to design something that fits into this frame? That's a central dilemma. This is something that no one has done before, so you have to invent how to combine things, and then reality is not always as you thought it was and this will not become apparent before you test it. Therefore, the development is primarily test driven even though simulations, especially of the mechanics surrounding the sensors, are used when appropriate.
Company $\mathrm{F}$ develops personal consumer devices and experiences challenges with integrating switches into mechanical assemblies. Often, the challenges are due to long tolerance chains, but in one example the challenge emerged due to a lack of coordination or system overview in the interface between a hall sensor and the mechanical part that it is activating it: We had a hall sensor with a magnet and we had agreed on some specific angular motion and then we had positioned the magnets in the right position in relation to this. But then it has been decided to change the angular motion at a later stage, and then you suddenly end up in the outer edge of what the sensor can detect. This was a challenge because the manufacturing tools where already set. The interviewee ascribes this to an unfortunate decision at late stage in the development project and concludes that once again, it is the integration that causes the angle to be off in relation to the hall sensor. Functional performance often have to be balanced with tactility, i.e. the costumer experience is central. This can sometimes be a challenge when you have to design something that is narrow and slim and must not take up too much space, which indicates that the trade-off is at least three dimensional.
Company $\mathrm{G}$ are integrating sensors into devices for personal medical use. Often, the mechanical device is already highly optimized for robustness when the sensor system design is initiated and because a deep integration is required for ease of use, the retrofitting process is challenging: If you want to attach a sensor system on something you have already designed and was not designed to be a sensor system, then it is extra challenging. [...] The factory is already there and the production is unwilling to change the components. Then comes the multi-disciplinarity: It's always in the interfaces [between disciplines, auth.] because sometimes when you are in one discipline then you lose the overview [...] I think we do try to focus on the interfaces, [...] but when it comes to the interfaces where you have a discipline containing both mechanics, electronics and software, then you are missing something. And chemistry as well. In terms of robust design, early assessments for mechanics are already in place. The electronics engineers relate: We might envy mechanics a bit. It is nice to have something as tangible even if it is complex. [...] Something to measure, a method for calculation. That's what we are missing for electronics.
Company I's core product is to control industrial processes and they design and integrate sensors to improve the performance of this control at a reasonable cost: Often, there is something we can buy but it becomes too expensive to put it together, because it doesn't fit perfectly. Therefore [...] we have our own factories where we try to develop something that fits [our product, auth.]. And that's because when we integrate, what I call deep integration, then we can reduce the cost. On the challenges with sensor system design, one of the interviewees related: It is almost always the integration that is the hardest part - where things happen that we are not able to foresee. It is almost always because we are working in an interface where many disciplines interact. [...] There is mechanics, there is electronics and there is high temperatures, there is software and then the communication. It is the interaction between all of these disciplines that gives the challenge, because none of us can cover all of those disciplines. So being able to communicate across those disciplines is central when we are talking about sensing. Multi-physics simulations is not the solution yet: When we simulate it, then it is simply front-edge. The simulation tool are only on the edge of being able to connect the domains.

Table 3. Company profiles in the deep integration/narrow technology square in Fig. 1. 


\section{Challenges with wear and mechanical joining processes}

Company C (Sensing)

Company C's sensing element is mounted in a housing that can be attached to the industrial system through standard interfaces. However, some customers have been interested in integrating the sensing element deeper into their own system: We have had some projects with customers, where they want to reduce the cost by not buying our [housing and standard interface, auth.] but only our sensing element [...] and maybe even have the calibration software in their own controller. We have not succeeded with this properly yet [because of costs and subcontractor dependencies, auth.]. But we have examples from customers, where they have done it with some of our competitors and had problems with it, and then we have substituted that solutions with a standard sensor or modified sensor so that it could fit. Apart from these challenges, the interviewees related that they are beyond what normal electronics are used for in terms of temperatures, why segregated DFMEA approaches for mechanics and electronics have been linked to address challenges of designing for unpredictable environments based on very standard and generic specifications from costumers, which are not fully reflecting the real world application.
Company D has a long tradition within development of sensors for their core business. The technological focus is narrow but they are looking into expanding their portfolio to accommodate digitalisation and IoT. We rarely develop [a sensor, auth.] from scratch. With most, if not all, we draw on experiences from earlier products. We take a previous design, we change a few things, and then we put it into a simulation program where we try to simulate its behaviour. The physics is the starting point for every development project and they use multi-physics simulations: We do whatever we can to assess the sensor performance for a given design before we prototype anything. Due to the extensive experience with the technology, the multi-physical behaviour is not the main challenge: It is in the separate domains we see the biggest challenges. Examples of these challenges are gluing of titanium plates as well as temperature isolation and mitigation of vibrations of electrical components. Other challenges include spending a lot of time, effort and resources on component qualification tests. They mitigate variation primarily through tight mechanical tolerances and quality control of all electronic components.
Company $\mathrm{H}$ develops and builds large industrial machinery and integrate sensors to enhance the control. Their production volume is low and their standard machinery are not changed too much between design iterations as the company profits a lot from aftersales and maintenance services. Their development process is divided into mechanical, electrical and software design. When the machine has been built and the task of designing the control system reaches the software department it is a challenge to gather all necessary details: Often it is just a question of adjusting the software to the reality. They have limited access to full scale field tests before commissioning due to the size of the machinery, so the design of the control software is assessed through virtual simulations. Company $\mathrm{K}$ has experienced challenges with sensors due to mechanical wear on the surface of a capacitive scale and due to dust particles disturbing the laser of position sensors. Nevertheless, sensor system challenges only leads to delays of 2-4 weeks and hence the if it works it works-methodology is successful.

Table 4. Company profiles in the shallow integration/narrow technology square in Fig. 1. 


\section{Challenges with technological domestication}

\section{Company A (Sensing)}

Company A is developing sensors, hardware and software for digital integration of sensors into large industrial systems. The interviewee is involved in vertical integration which is the hardware connecting the sensors on the shop floor with the higher level system. The interviewee related that the pace of the technological evolution forced them to develop new product version through very short cycles: Computing power is continuously enhanced, the whole industry [...] is enormously moving. There are continuously new software stacks, new vertical stacks and this is why we need to be fast and cannot afford a years' development cycle. The goal is three months development times. The interviewee reported how a platform oriented design approach makes the three month development cycle possible despite certification bureaucracy as it allows them to combine pre-qualified components. Then they only have to go through system tests before they would be ready to launch a new version. One of the most challenging pre-qualification activities is temperature simulations used to balance the trade-off temperature vs. size of the housing, which refers to adequate cooling of the hardware components.
Company B develops a wide range of sensors for different industries, both customand ready-made. The interviewee related that the most challenging part of sensor system design was to gather all requirements including specific test details: The challenge is how to get the information, the use cases, the environmental condition, the frame conditions in the application and put it together. Furthermore, the interviewee expressed that the pace of the technological evolution was challenging: The technology is continuously developing, so we have to improve the parameters of the sensors, which drives us more and more to the technical limits. Sensitivity gets higher and higher and then the accuracy of whatever you do, the circuit design and the production processes gets more and more challenging. This also aggravates the trade-off between manufacturing and performance: For example, I can produce a sensor in one part, then it is more flimsy for the production to assemble it, or I can do it in two parts, then it is easy to place it together. But if you have two parts then you have the disadvantage for example that things can move apart and can add on tolerances, which is a disadvantage for the accuracy of the product.
Company $\mathrm{L}$ is a consultancy focusing on mechatronic product development. The interviewee relates that assignments can be solved in a lot of different ways. You could say: Should we do this in hardware, software or mechanics? Of course, you can sometimes have a tug of war about how to solve it in the best way. But it rarely develops into any real dilemmas. Often it is all about reaching a common understanding of the pros and cons for each discipline, which can be a challenge in electromechanical interfaces: It is very typical for mechanics and electronics, because it is two very different worlds that meet and sometimes it can be hard for a mechanics-person to understand why the electronics can be so damn troublesome and take so much of the budget. And vice versa. Therefore, they often take this discussion internally to achieve a balanced perspective on the adjacent disciplines. Due to the variety of the projects, they have a pragmatic and test oriented approach to design assessments. One reason for this is the following: Sometimes you can simulate a whole circuit pretty precisely but you could have built it and tested whether you were on the right track in half the time.
Company $\mathrm{M}$ focuses on enabling IoT through a wide range of sensing technologies. They strive to build and test prototypes as early as possible. One of the interviewees would always prefer to use real data for the development of software rather than simulated data. The interviewee frequently used the mantra junk in, junk out and relates: To use a simulation model is something that only makes sense in my mind if you have a strong theory domain. You really have to know what you are dealing with. For every new costumer they almost always have a new sensor and application, but the needed familiarisation buffer differs: If we are familiar with the sensors then we know a bit more about the risks. That makes us adjust the time horizon. If we are not familiar with the sensors but the scope is somehow limited, like temperature, $\mathrm{CO}_{2}$ or humidity, which are sensors that outputs raw values, then there are smaller risks. But when the sensors have to be mounted or large amounts of data like vibrations data are outputted, then the time horizon has to be increased. And when we make mistakes in these projects then it will have consequences for the delivery on top of other influencing factors like manufacturers, deliveries and viruses, and what else.

Table 5. Company profiles in the shallow integration/wide technology square in Fig. 1. 


\section{Challenges with integrating sensing technology and mechanics}

\section{Company J (Industrial) Company K (Consulting)}

Company $\mathbf{J}$ develops large Company $\mathrm{K}$ is consulting industrial equipment per- companies on sensor sysforming in very harsh envi- tems for medical devices. ronments. The sensor sys- The interviewee related that tems are monitoring many the early connection with different processes with a the customer was critical wide range of technolo- for specifying the requiregies. Most sensor sys- ments: Understanding if the tem development projects main customer has a road are based on technologies map and what we are dethat are already applied signing today may become in other industries. The just a starting point of next main challenge is integra- generations, so we need to tion and only in special think about some modularcases new technology is ity and scalability or if they needed. The machines were are just looking for a retypically designed before allycost optimised solution, sensoring was considered. single design cycle, that is Only in cases where there very minimal and will not is either a special need or allow any prototype created there is a patent opportu- in the future or derivatives, nity do we consider devel- but will be very very close oping proprietary technol- to the minimal cost of a soogy. Maturing of technol- lution, for example for a ogy to new applications is disposable solution. To ada major challenge: We typ- dress the variety of comproically need a few iterations mises between cost and acto arrive at a satisfactory curacy and to save valuable maturity level before we go development time, Comto the customer, but those it- pany $\mathrm{E}$ are collecting senerations require some tests sors in a pre-qualification that we are hard to perform database: When you are in a laboratory. The inabil- typically going to use new ity to perform these tests technologies, you can find lies in the size of the in- new components that might dustrial equipment and its have some bugs that have remote location. They are not been understood yet, so occupied with finding work- you need to spend more arounds to be able to do it time in simulations, mathe- by testing in other indus- matical analysis and chartries for example. acterisation on the building block itself. You need to bring everything at the same maturity level in terms of knowledge.

Table 6. Company profiles in the deep integration/wide technology square in Fig. 1. 


\section{Table Caption List}

Table 1. Semi-structured interview guide themes and example questions

Table 2. General challenges among the case companies identified through inductive mapping

\section{Figure Caption List}

Matrix typology for Companies A-M. Common challenges are included in each quadrant, I-IV. 